\title{
Brain-derived neurotrophic factor (BDNF) and type 2 diabetes. Reply to Lambert GW et al (letter)
}

\author{
K. S. Krabbe • A. R. Nielsen • R. Krogh-Madsen • \\ P. Plomgaard • P. Rasmussen • C. Erikstrup • \\ C. P. Fischer • B. Lindegaard • A. M. W. Petersen • \\ S. Taudorf • N. H. Secher • H. Pilegaard • \\ H. Bruunsgaard • B. K. Pedersen
}

Received: 5 June 2007 / Accepted: 6 June 2007 / Published online: 19 July 2007

(C) Springer-Verlag 2007

Keywords Brain $\cdot$ Glucose $\cdot$ Neurotrophin

\begin{tabular}{|c|c|}
\hline Abbre & ations \\
\hline Av & arterial-venous \\
\hline BDNF & brain-derived neurotrophic factor \\
\hline MDD & major depressive disorder \\
\hline
\end{tabular}

To the Editor: We thank G. W. Lambert, M. P. Schlaich and M. D. Esler for their interest [1] in our paper [2]. As indicated by the title, our main interest was to examine the relationship between brain-derived neurotrophic factor (BDNF) and blood glucose. Because patients with type 2 diabetes have an increased prevalence of major depressive disorder (MDD) and MDD is associated with decreased blood levels of BDNF we controlled our analyses for

K. S. Krabbe $(\square) \cdot$ A. R. Nielsen $\cdot$ R. Krogh-Madsen •

P. Plomgaard · C. Erikstrup · C. P. Fischer · B. Lindegaard •

A. M. W. Petersen $\cdot$ S. Taudorf $\cdot$ H. Pilegaard $\cdot H$. Bruunsgaard $\cdot$

B. K. Pedersen

The Centre of Inflammation and Metabolism, Department of Infectious Diseases 7641, Rigshospitalet, Faculty of Health

Sciences, University of Copenhagen,

Copenhagen, Denmark

e-mail: karen.krabbe@dadlnet.dk

P. Rasmussen • N. H. Secher $\cdot$ H. Pilegaard • B. K. Pedersen The Copenhagen Muscle Research Centre, Rigshospitalet, Faculty of Health Sciences, University of Copenhagen, Copenhagen, Denmark

\section{H. Pilegaard}

The August Krogh Building, Institute of Molecular Biology, University of Copenhagen,

Copenhagen, Denmark current intake of antidepressive medication as a marker of MDD. We agree with Lambert and colleagues that we probably underestimated the prevalence of MDD in our study sample. Furthermore, if this is the case, it most probably applies to both the NGT group (5 of 103) and the diabetes group (5 of 96), thus introducing a systematic, but equal, underestimation of MDD. Nonetheless, these patients were not specifically investigated, and a dedicated study on the population of patients with MDD is needed.

In addition, we evaluated the arterial-venous (Av) differences in BDNF concentration across the brain in healthy young men, which revealed an output from the brain at rest (arterial concentration-venous concentration [means \pm SEM]: $648 \pm 122-1242 \pm 259=-594 \pm 254 \mathrm{pg} / \mathrm{ml})$ that was inhibited after $2 \mathrm{~h}$ of hyperglycaemic clamp (774 $\pm 160-772 \pm 334$ $\mathrm{pg} / \mathrm{ml}=2 \pm 303 \mathrm{pg} / \mathrm{ml}$ ). For the purpose of measuring Av concentration differences we used the right internal jugular vein, well aware of the work from Australia [3] demonstrating asymmetry in venous drainage from the brain. Accordingly, we cannot confirm whether the determined Av differences represent the release of $\mathrm{BDNF}$ from deeper structures of the brain, as demonstrated for catecholamines in hypertensive patients by the Australian group. The vein was visualised by ultrasound; we can state only that none of the veins used for catheterisation were small, although some were collapsed at the time of catheterisation and the procedure was helped by performing a Valsalva manoeuvre. Whether there exists a difference between release of BDNF from deeper structures in the brain probably drained by a small (and most often the left) vein or from the cerebral cortex, drained most often by the larger right vein, was not evaluated. However, as the right vein was catheterised, it is most likely that the samples predominately contained blood draining from the hemi- 
spheres. We do not routinely perform a technetium scan of brain circulation prior to catheterisation, although such an evaluation has been made [4], inspired by the work from Australia.

We can only agree that an evaluation of the role of BDNF in blood glucose regulation, and its potential role in MDD in particular, requires a more detailed evaluation, and we hope that our preliminary results provide some inspiration for this research.

Duality of interest The authors declare that there is no duality of interest associated with this manuscript.

\section{References}

1. Lambert GW, Schlaich MP, Esler MD (2007) Brain derived neurotrophic factor (BDNF) release from the human brain in patients with type 2 diabetes-possible influence of venous anatomy and comorbid major depressive disorder. Diabetologia DOI 10.1007/s00125-007-0756-3

2. Krabbe KS, Nielsen AR, Krogh-Madsen R et al (2007) Brainderived neurotrophic factor (BDNF) and type 2 diabetes. Diabetologia 50:431-438

3. Ferrier C, Jennings GL, Eisenhofer G et al (1993) Evidence for increased noradrenaline release from subcortical brain regions in essential hypertension. J Hypertens 11:1217-1227

4. Ide K, Secher NH (2000) Cerebral blood flow and metabolism during exercise. Prog Neurobiol 61:397-414 